EXTENDED REPORT

\title{
Degree, duration, and causes of visual loss in uveitis
}

\author{
O M Durrani, N N Tehrani, J E Marr, P Moradi, P Stavrou, P I Murray
}

Br J Ophthalmol 2004;88:1159-1162. doi: 10.1136/bjo.2003.037226

See end of article for authors' affiliations

.....................

Correspondence to: Professor P I Murray, Academic Unit of Ophthalmology, Division of Immunity and Infection Birmingham and Midland Eye Centre, Sandwell and West Birmingham Hospitals NHS Trust, City Hospital Dudley Road, Birmingham B18 7QU, UK; P.I.Murray@ bham.ac.uk

Accepted 31 January 2004

\begin{abstract}
Background/aims: Uveitis is a major cause of visual morbidity in the working age group. The authors investigated the duration, degree, and causes of visual loss in uveitis patients with the aim of better defining the visual morbidity and identifying potential risk factors.

Methods: A retrospective, non-interventional, observational survey of 315 consecutive patients attending a tertiary referral uveitis service.

Results: The mean duration of follow up was 36.7 months. Reduced vision ( $\leqslant 6 / 18)$ was found in $220 /$ $315(69.95 \%)$ of the patients with a subset of 120 patients having vision $\leqslant 6 / 60$. Unilateral visual loss occurred in 109 (49.54\%), while 111 (50.45\%) had bilateral loss. The mean duration of visual loss was 21 months. Of the 148 patients with pan-uveitis, 125 (84.45\%) had reduced vision, with 66 (53\%) having vision $\leqslant 6 / 60$. Main causes of visual loss were cystoid macular oedema (CMO) (59/220, 26.8\%), cataract $(39 / 220,17.7 \%)$, and combination of CMO and cataract $(44 / 220,20 \%)$. The following were predictive of a poorer visual prognosis: pan-uveitis $(p=0.0005)$, bilateral inflammation $(p=0.0005)$, increasing duration of reduced vision $(p=0.0005)$, an Indian or Pakistani ethnic background $(p=0.004)$, and increasing patient age $(p=0.02)$.

Conclusion: Prolonged visual loss occurred in two thirds of uveitis patients, with $70(22 \%)$ patients meeting the criteria for legal blindness at some point in their follow up. Older patients with bilateral inflammation and an increasing duration of reduced vision are at the greatest risk of severe visual loss $(\leqslant 6 / 60)$. CMO and cataract were responsible for visual loss in $64.5 \%$ of patients.
\end{abstract}

to July 2003 found no studies of the economic cost of blindness from uveitis.

The aims of this retrospective, observational, non-interventional study are to investigate the degree, duration, and causes of visual loss in uveitis patients. The duration of uveitis associated visual loss has not previously been investigated. We feel this is a key factor in providing a better insight into the socioeconomic implication of this disease, by not only identifying those patients with permanent visual loss but also any subgroup of patients with a severe but temporary visual disability.

\section{PATIENTS AND METHODS}

The medical records of 315 consecutive patients attending a tertiary referral uveitis service at the Birmingham and Midland Eye Centre over a two year period (January 1998 to December 2000) were reviewed. All patients had undergone a detailed clinical history and ocular examination including visual acuity, pupillary reactions, slit lamp examination, intraocular pressure (IOP) measurement, posterior pole biomicroscopy, and indirect ophthalmoscopy. Where appropriate, patients were investigated for any underlying disease association. The data recorded included age, sex, race, duration of follow up, and laterality of inflammation and causes of visual loss. Patients were identified as having permanent ocular damage if they had irreversible changes, such as macular scarring or atrophy, lamellar macular hole formation, optic atrophy, and so on. The anatomical site of inflammation was used to classify the uveitis according to the recommendations of the International Uveitis Study Group.' Snellen visual acuity was recorded at each visit. For the purpose of this study, visual loss was defined as best corrected vision of $6 / 18$ or worse. Patients with visual morbidity were subdivided into two groups: those with

Abbreviations: $\mathrm{AU}$, anterior uveitis; $\mathrm{CMO}$, cystoid macular oedema, $I O P$, intraocular pressure; LO, lens opacity; VQOL, vision quality of life. 
moderate visual loss defined as $6 / 18$ to $6 / 36$, and those with severe visual reduction defined as $\leqslant 6 / 60$. In addition to the degree of reduced vision, the duration of visual loss was also calculated. As the level of vision in uveitis may fluctuate with varying severity or sequelae of inflammation, the total duration of visual loss was calculated by adding the duration of individual episodes. The causes of visual impairment were also recorded.

Statistical analysis was carried out using MINITAB statistical software, version 13.1 (Minitab Inc, University Park, PA, USA). The impact of patient sex, race, type of uveitis, age, and age of onset on visual loss, was analysed using binary logistic regression while the association between duration, laterality of inflammation, and severity of visual loss were analysed using a two sample $t$ test and MannWhitney test.

\section{RESULTS}

A total of 315 consecutive uveitis patients with a mean age of 48 years (range 7-86 years) and a mean duration of follow up of 36.71 months (standard deviation 53.73, range 2-360 months) were included in the study. Patient demographics are presented in table 1 and the type of uveitis in table 2. Within this cohort of 315 patients, 220 (69.95\%) had visual loss of $\leqslant 6 / 18$ in at least one eye. Of this subset of 220 patients with unilateral or bilateral reduced vision, 100 $(45.45 \%)$ had moderate visual loss (6/18-6/36), and 120 $(54.54 \%)$ had severe visual loss of $\leqslant 6 / 60$. Some degree of permanent visual damage was found in 54/220 (24.5\%) patients; 11 patients had unilateral and 46 had bilateral damage. Only 36 of the 315 (11.4\%) patients met the WHO blindness criteria.

Of the 315 patients chronic unilateral intraocular inflammation was present in $107(34 \%)$ patients and resulted in reduced vision (moderate and severe) in 68 of those $(63 \%)$. Moderate loss was in 19/68 (28\%), and 49/68 (72\%) had severe reduction in vision. Bilateral inflammation was present in 208/315 (66\%) patients with 152/208 (73\%) having moderate or severe visual loss; $41 / 152$ (27\%) lost vision in one eye and $111 / 152(73 \%)$ in both eyes. Of the 111 patients with bilateral visual loss, 70 (63\%) experienced severe visual loss, thus meeting the criteria for legal blindness in many parts of the world.

The mean duration of visual loss was 20.35 months for patients with moderate visual loss and 22.8 months in patients with severe loss of vision. In patients with unilateral visual loss the mean duration was 20 months whereas it was 42.61 months in patients with bilateral visual morbidity.

Visual loss was more common in patients with pan-uveitis (125/148, 84.45\%), followed by anterior uveitis (AU) (45/81, $55.5 \%)$. Of the patients with AU, 40 had acute AU and 41 had

\begin{tabular}{ll} 
Table $1 \quad$ Patient demographics \\
\hline Patients ( $\mathbf{n}=315)$ & \\
\hline Age (years) & 48 \\
Mean & $7-86$ \\
Range & 3 \\
Follow up (years) & $10.3-30)$ \\
Mean & $121(38.4 \%)$ \\
Range (years) & $194(61.6 \%)$ \\
Sex & $190(60.3 \%)$ \\
Male & $88(27.9 \%)$ \\
Female & $35(11.1 \%)$ \\
Race & $1(0.6 \%)$ \\
Caucasian & \\
Indian/Pakistani & Afro-Caribbean \\
Mixed race & \\
\hline
\end{tabular}

Table 2 Visual loss and diagnosis

\begin{tabular}{|c|c|c|c|c|}
\hline \multirow[b]{2}{*}{ Diagnosis } & \multirow{2}{*}{$\begin{array}{l}\text { Total } \\
\text { population } \\
(\mathrm{n}=315)\end{array}$} & \multirow{2}{*}{$\begin{array}{l}\text { Patients with } \\
\text { visual loss } \\
\text { (n=220, } \\
69.84 \% \text { ) }\end{array}$} & \multicolumn{2}{|l|}{ Severity* (\%) } \\
\hline & & & Moderate & Severe \\
\hline Pan-uveitis & 148 & $125(84.45 \%)$ & 59 (47) & $66(53)$ \\
\hline Anterior uveitis & 81 & $45(55.55 \%)$ & & \\
\hline Acute & 40 & $19(47.5 \%)$ & $9(47.36)$ & $10(52.63)$ \\
\hline Chronic & 41 & $26(63.41 \%)$ & $10(38.46)$ & $16(61.53)$ \\
\hline $\begin{array}{l}\text { Intermediate } \\
\text { uveitis }\end{array}$ & 33 & $17(51.51 \%)$ & $12(70)$ & $5(30)$ \\
\hline $\begin{array}{l}\text { Fuchs' } \\
\text { heterochromic } \\
\text { uveitis }\end{array}$ & 29 & $18(62 \%)$ & 7 (39) & $11(61)$ \\
\hline Posterior uveitis & 11 & $7(63.6 \%)$ & $3(43)$ & $4(57)$ \\
\hline Sclero-uveitis & 13 & $8(61.5 \%)$ & $3(38)$ & $5(62)$ \\
\hline
\end{tabular}

chronic AU. Visual reduction was more common and severe in the chronic AU subgroup (table 2).

Of the patients under the age of 40 years $(n=111,35.5 \%)$, $40 \%$ had pan-uveitis and $24.8 \%$ had bilateral visual loss. In the $40-60$ years age group $(\mathrm{n}=120,38 \%), 48.3 \%$ had panuveitis and $29.8 \%$ had bilateral loss of vision. For patients over 60 years of age $(\mathrm{n}=87,26.5 \%)$ pan-uveitis was found in $46 \%$ of the cases but prevalence of bilateral visual morbidity increased to $49 \%$.

In the 220 patients with visual loss the main causes were cystoid macular oedema (CMO) $(\mathrm{n}=59,26.8 \%)$, cataract $(\mathrm{n}=39,17.7 \%)$, and a combination of CMO and cataract $(\mathrm{n}=44,20 \%)$. A variety of other causes including glaucoma, band keratopathy, vitreous debris, severe vitritis, retinal detachment, optic neuropathy, epiretinal membrane formation, and submacular fibrosis resulted in visual loss in an additional $78(35.5 \%)$ of the patients (table 3 ).

The following were found to be strong predictors of visual loss (table 4$)$ : pan-uveitis ( $\mathrm{p}=0.0005, \mathrm{OR}=4.14,95 \%$ CI 2.37 to 7.24), an Asian (Indian or Pakistani) race $(p=0.004$, $\mathrm{OR}=2.65,95 \% \mathrm{CI} 1.37$ to 5.11 ), and increasing patient age $(p=0.02, O R=1.02,95 \%$ CI 1.0 to 1.04$)$. Age of onset of uveitis and patient sex were not found to have a statistically significant impact on vision. Patients with an increasing duration of reduced vision $(\mathrm{p}=0.0005, t$ value $=-4.62,95 \%$ $\mathrm{CI}=-0.5099$ to -0.174$)$, and bilateral inflammation were at a much higher risk of visual loss $(\mathrm{p}=0.0005, t$ value $=-4.62$, $95 \%$ CI -0.556 to -0.224 ).

\section{DISCUSSION}

In our cohort of 315 patients, 220 (69.9\%) experienced visual loss $\leqslant 6 / 18$ with $50.45 \%$ having bilateral reduced vision. This is higher than previously reported, ${ }^{1}{ }^{12}{ }^{13}$ and may be due to our definition of visual loss as an acuity of $\leqslant 6 / 18$, as we felt that visual reduction to this level was more likely to interfere with daily life. This is supported by a recent study by Evans

Table 3 Causes of visual loss in 220 patients

\begin{tabular}{ll}
\hline Causes of visual loss & Number (\%) \\
\hline Cystoid macular oedema (CMO) & $59(26.8)$ \\
Lens opacity (LO) & $39(17.7)$ \\
CMO+LO & $44(20)$ \\
Vitreous debris & $24(10.9)$ \\
Macular pathology (scarring, atrophy, hole) & $17(7.7)$ \\
Optic neuropathy (non-glaucomatous) & $11(5)$ \\
Glaucoma & $11(5)$ \\
Retinal detachment & $8(3.6)$ \\
Multiple factors (other than CMO, LO) & $7(3.1)$ \\
\hline
\end{tabular}


Table 4 Factors predictive of visual morbidity in uveitis

\begin{tabular}{|c|c|c|c|}
\hline Factor & p Value & $\begin{array}{l}\text { Odds ratio/ } \\
t \text { value }^{*}\end{array}$ & $\begin{array}{l}95 \% \text { confidence } \\
\text { interval }\end{array}$ \\
\hline Pan-uveitis & 0.0005 & 4.14 & 2.37 to 7.24 \\
\hline $\begin{array}{l}\text { Bilateral } \\
\text { inflammation }\end{array}$ & 0.0005 & $*-4.62$ & -0.5561 to -0.2236 \\
\hline $\begin{array}{l}\text { Duration of visual } \\
\text { loss }\end{array}$ & 0.0005 & $*-4.01$ & -0.5099 to -0.1736 \\
\hline Indian/Pakistani & 0.004 & 2.65 & 1.37 to 5.11 \\
\hline Patient age & 0.019 & 1.02 & 1.00 to 1.04 \\
\hline
\end{tabular}

et $a l^{14}$ that also defines visual impairment as a vision $\leqslant 6 / 18$. Most other studies used the WHO definition of vision loss. ${ }^{12} 1516$ Also, being a tertiary referral centre, more patients are likely to suffer from severe, often bilateral uveitis. A similar pattern is seen in most studies from specialist centres with pan-uveitis being the most common diagnosis. ${ }^{17}{ }^{18}$ Results from population or community based studies are likely to have a different referral pattern with anterior uveitis as the most common type of uveitis. ${ }^{19} 20$ A recent study by Taylor and Keeffe ${ }^{21}$ suggests that economic blindness actually occurs when vision drops below 6/12, as vision below this level affects a person's ability to drive and function in the workplace. This is supported by a study by West et al that found vision less than 20/30 (6/9, logMAR 0.2) affected visually intensive tasks such as reading. ${ }^{22}$

Studies by Rothova et al and Bodaghi et al have investigated the incidence and aetiology of blindness in similar cohorts of patients but do not provide information on the duration of visual morbidity, or document temporary visual loss that is likely to reduce the quality of life and impair the economic productivity of these patients. ${ }^{12}{ }^{18}$ Our data suggest that loss of vision in uveitis occurs predominantly as a temporary, sometimes severe visual deterioration lasting weeks, months, or even years primarily from CMO, cataract, or a combination of the two. In most forms of uveitis, visual morbidity usually does not occur from a single episode of uveitis; rather recurrent episodes of inflammation cause cumulative damage. However some patients with severe disease can develop refractory CMO at an early stage whereas patients with Behçet's disease can develop devastating visual loss within days despite intensive immunosuppression.

In our study we used the IUSG classification to record the type of uveitis and found pan-uveitis to have a poorer visual outcome. The aetiology of the underlying inflammation, if known, must also be taken in to account as not all types of uveitis have the same impact on vision. Conditions such as Behçet's disease and birdshot retinochoroidopathy are likely to have a much worse prognosis compared with Fuchs' heterochromic uveitis syndrome, where visual prognosis is much better, though cataract formation occurs in most patients and causes reduced vision until cataract surgery is performed.

Considering that the mean duration of follow up was 36.7 months, $70 \%$ of the patients had some degree of visual loss for two thirds of that time. Difficulties in achieving control of intraocular inflammation result in delays in performing cataract surgery, while CMO is also unlikely to resolve in the presence of active disease. These patients are likely to suffer tremendous visual and socioeconomic hardship and may not qualify for visual disability registration. This dilemma is highlighted as only 36 out of 220 patients with visual morbidity in our cohort were eligible for blind registration, even though 70 patients $(22 \%$ of the total cohort) met the criteria for legal blindness at some point during their follow up. An additional 18 patients had some degree of permanent visual damage (7 bilateral and 11 unilateral) but did not fulfil the requirements of blind registration. The adverse impact of unilateral as well as bilateral visual reduction on quality of life is also well established. ${ }^{23-26}$ Two studies based on the Blue Mountains Eye Study cohort found that although bilateral visual morbidity results in reduced functional status and wellbeing that is comparable to a major medical condition, moderate to severe unilateral visual loss also has a measurable impact on quality of life. ${ }^{27} 28$ A study by the Royal National Institute for the Blind suggested that $34 \%$ of individuals lose jobs within two years of visual impairment. ${ }^{29}$ In the 1993 annual report of Research to Prevent Blindness, an estimated 2.3 million Americans suffered visual impairment because of uveitis. ${ }^{30}$ In the Netherlands in a hospital based study (1975-77), uveitis caused $6 \%$ of all blindness and ranked fifth after diabetic retinopathy, age related macular degeneration, retinal dystrophies, and glaucoma. ${ }^{9}$ As these studies do not include all uveitis cases and do not report separately on the complications of uveitis, such as cataract and glaucoma, this percentage is probably higher. ${ }^{1}$ The estimated cost of blindness to the United States economy from uveitis is equal to the cost of blindness from diabetes where the incidence of diabetes is twice as high as uveitis. ${ }^{9}$ Additional morbidity from associated systemic diseases is present in $25-50 \%$ of the patients. $^{93132}$

We recently investigated the correlation between tests of visual function and perceived visual ability recorded with a vision quality of life questionnaire (VQOL) for patients with uveitis. ${ }^{23}$ We studied 132 patients with various types of uveitis and found that binocular high contrast visual acuity was able to predict VQOL $(\mathrm{p}<0.01)$, and VQOL was worst in younger patients with poor binocular visual acuity $(p<0.001)$. VQOL also declined with reduced uniocular performance of high contrast visual acuity of the better $(p=0.0012)$ and worse eye $(p=0.015)$, in agreement with the findings of the Blue Mountain Eye Studies. ${ }^{27}{ }^{28}$ Although VQOL instruments have been validated in English, this is not the case for many other languages. ${ }^{33}$ We live in a multiracial and multicultural society, but we are unable to use some these tools on many of our patients from other parts of the world as no validated translations exist.

Patients with bilateral intraocular inflammation had a poorer visual prognosis compared with the other groups in our cohort $(p=0.0005)$ : the mean duration of visual loss was found to be twice as long (42.6 months) as patients with unilateral inflammation (20 months), with almost three out of four having reduced vision. Our experience would suggest that these patients tend to have more severe inflammation that is difficult to control. Pan-uveitis was the most common diagnosis followed by anterior uveitis, intermediate uveitis, and Fuchs' heterochromic uveitis (table 2). Bodagi et al, in their study of 927 patients with severe uveitis, also found pan-uveitis as the most common diagnosis followed by anterior uveitis. They concluded that the results of their study could not be applied to the general population because of the tertiary nature of the patient population; this conclusion also applies to our cohort. ${ }^{18}$ Rothova et al also found pan-uveitis to have a worse visual prognosis, which was in agreement with our findings. ${ }^{12}$

Age of onset of uveitis was not found to be predictive of severity of visual loss in our cohort; this may be related to the fact that none of the patients had JIA, a known cause of visual morbidity in children. ${ }^{34}$ An increasing patient age, however, was found to have an adverse impact on vision $(p=0.019)$. This is probably related to an increasing prevalence of pan uveitis and bilateral disease with increasing age, though Darrell et al did not find age to be a risk factor. ${ }^{2}$ None of our patients had age related macular degeneration, 
but the possibility of age related cataract contributing to visual reduction cannot be ruled out in this subgroup.

A strong association was found between duration of visual loss and its severity $(p=0.0005)$, with an increasing duration of visual morbidity being strongly associated with poorer visual acuity. When control of inflammation is difficult, CMO persists and permanent macular changes including lamellar hole formation may occur, and any delay in cataract surgery may result in progressive deterioration of vision.

Cataract and CMO either alone or in combination were responsible for visual loss in $64.5 \%$ of the patients in our cohort, in agreement with Bodaghi et al. ${ }^{18}$ Rothova et al, investigating causes of visual loss in 582 patients with intraocular inflammation, found $\mathrm{CMO}$ to be the most common cause of decreased vision (26\%) followed by cataract $(19 \%){ }^{12}$ Although cataract surgery carries an excellent prognosis in most types of uveitis, ${ }^{35}$ it is acknowledged that the eye should be inflammation free for at least three months before surgery (Fuchs' heterochromic uveitis being the most obvious exception), thus the patient may suffer prolonged visual morbidity until the eye is quiet enough for surgery to be undertaken.

Racial predisposition for diseases like Behçet's disease, Vogt Koyanagi Harada disease, and sarcoidosis are well known $^{36-38}$ but an association between ethnic background and visual loss in uveitis has not been described before. Our results suggest that an Indian/Pakistani ethnic background was predictive of a poorer visual prognosis $(p=0.004)$. The clinical significance of this association needs further investigation. Perhaps this subgroup is more prone to develop complications associated with uveitis and requires more aggressive control of inflammation, but other factors such as poor compliance due to language difficulties and cultural differences are also possible. Our cohort also had a higher preponderance or female patients $(61.6 \%)$. This is unusual as most studies do not report a higher susceptibility in either sex. Merrill et al also found a higher percentage of women in their study $(62 \%) \cdot{ }^{17}$ As their study is based on patients from a tertiary referral service, it raises the possibility that women may be more susceptible to more severe uveitis compared with men but this needs further investigation.

Recent years have seen significant improvement in the management strategies for uveitis, but despite this visual loss occurs in up to $35-40 \%$ of the patients. ${ }^{12}{ }^{13}$ A review of the literature suggests that very few data exist on the incidence and prevalence of visual loss and blindness from uveitis. This is surprising considering the likely socioeconomic impact of the disease. Most studies investigating the causes of blindness look at an older age group and do not classify uveitis as a separate entity. Epidemiological studies investigating blindness in the working age group are badly needed to define the true impact of uveitis on visual morbidity. ${ }^{33}$

\section{Authors' affiliations}

O M Durrani, P I Murray, Academic Unit of Ophthalmology, Division of Immunity and Infection, University of Birmingham, UK

N N Tehrani, J E Marr, P Moradi, P Stavrou, Birmingham and Midland Eye Centre, Sandwell and West Birmingham Hospitals NHS Trust, City Hospital, Birmingham, UK

\section{REFERENCES}

1 Suttorp-Schulten MSA, Rothova A. The possible impact of uveitis in blindness: A literature survey. Br J Ophthalmol 1996:80:844-8

2 Darrell RW, Wagner HP, Kurland LT. Epidemiology of uveitis: incidence and prevalence in a small urban community. Arch Ophthalmol 1962;68:502-14.
3 Mortensen KK, Slolie AK, Goldschmidt E. Uveitis, eine epdemiologische Unterschung. Ger Stsch Ophthalmol Ges 1981;78:97-101.

4 Vadot $E$, Barth $E$, Billet $P$. Epdemiology of uveitis- preliminary results of a prospective study in Savoy. In: Saari K, ed. Uveitis update. Amsterdam: Elsevier, 1984:13-16.

5 Baarasma GS. The epidemiology and genetics of endogenous uveitis: a review. Curr Eye Res 1992;11(Suppl): 1-9.

6 Tran VT, Auer C, Guex-Crosier Y, et al. Epidemiology of uveitis in Switzerland. Ocul Immunol Inflamm 1994:2:169-76.

7 Miettinen R. Incidence of uveitis in Northern Finland. Acta Ophthalmol (Copenh) 1977;55:252-60.

8 Dandona L, Dandona R, John RK, et al. Population based assessment of uveitis in an urban population in southern India. Br J Ophthalmol 2000;84:706-9.

9 ten Doesschate J. Causes of blindness in the Netherlands. Doc Ophthalmol 1982;52:270-85.

10 Krumpaszky HG, Klauss V. Causes of blindness in Bavaria. Evaluation of a representative sample from blindness compensation records of Upper Bavaria. Klin Monatsbl Augenheilkd 1992;200.

11 Nussenblatt RB. The natural history of uveitis. Int Ophthalmol 1990;14:303-8.

12 Rothova A, Suttorp-van Schulten MS, Frits Treffers W, et al. Causes and frequency of blindness in patients with intraocular inflammatory disease. Br J Ophthalmol 1996;80:332-6.

13 Couto C, Merlo JC. Epidemiological study of patients with uveitis in Buenos, Argentina. Amsterdam, New York: Kugler Publications, 1993.

14 Evans JR, Fletcher AE, Wormald RP, et al. Prevalence of visual impairment in people aged 75 years and older in Britain: results from the MRC trial of assessment and management of older people in the community. Br J Ophthalmol 2002;86:795-800.

15 Kotaniemi K, Aho K, Kotaniemi A. Uveitis as a cause of visual loss in arthritides and comparable conditions. J Rheumatol 2001;28:309-12.

16 Rosner RS. Uveitis and blindness. Med Trial Tech Q 1967;14:39-42.

17 Merrill PT, Kim J, Cox TA, et al. Uveitis in the southeastern United States. Curr Eye Res 1997; 16:865-74.

18 Bodaghi B, Cassoux N, Wechsler B, et al. Chronic severe uveitis: etiology and visual outcome in 927 patients from a single center. Medicine (Baltimore) $2001 ; 80: 263-70$

19 McCannel CA, Holland GN, Helm CJ, et al. Causes of uveitis in the general practice of ophthalmology. UCLA Community-Based Uveitis Study Group. Am J Ophthalmol 1996;121:35-46.

20 Paivonsalo-Hietanen T, Vaahtoranta-Lehtonen $\mathrm{H}$, Tuominen J, et al. Uveitis survey at the University Eye Clinic in Turku. Acta Ophthalmol (Copenh) 1994;72:505-12.

21 Taylor HR, Keeffe JE. World blindness: a 21 st century perspective. Br J Ophthalmol $2001 ; 85: 261-6$.

22 West SK, Rubin GS, Broman AT, et al. How does visual impairment affect performance on tasks of everyday life? The SEE Project. Salisbury Eye Evaluation. Arch Ophthalmol 2002;120:774-80.

23 Gardiner AM, Armstrong RA, Dunne MC, et al. Correlation between visual function and visual ability in patients with uveitis. $\mathrm{Br} J$ Ophthalmol 2002;86:993-6.

24 Schiffman RM, Jacobsen G, Whitcup SM. Visual functioning and general health status in patients with uveitis. Arch Ophthalmol 2001;119:841-9.

25 Broman AT, Munoz B, Rodriguez J, et al. The impact of visual impairment and eye disease on vision-related quality of life in a Mexican-American population: proyecto VER. Invest Ophthalmol Vis Sci 2002;43:3393-8.

26 Brown GC. Vision and quality-of-life. Trans Am Ophthalmol Soc 1999;97:473-511.

27 Chia EM, Mitchell P, Rochtchina E, et al. Unilateral visual impairment and health related quality of life: the Blue Mountains Eye Study. Br J Ophthalmol 2003;87:392-5.

28 Chia EM, Rochtchina E, Wang JJ, et al. Impact of visual impairment on healthrelated quality of life: the Blue Mountains Eye Study. Invest Ophthalmol Vis Sci 2004;45:71-6.

29 Bruce I, McKennel E. Blind and partially sighted adults in Britain: the RNIB survey. London: Royal National Institute for the Blind, 1991.

30 Research to Prevent Blindness. Annual report 1993. New York: RPB, 1993.

31 Rothova A, Buitenhuis HJ, Meenken C, et al. Uveitis and systemic disease. Br J Ophthalmol 1992;76:137-41.

32 Smit RL, Baarsma GS, de Vries J. Classification of 750 consecutive uveitis patients in the Rotterdam Eye Hospital. Int Ophthalmol 1993;17:71-6.

33 Dandona R, Dandona L, McCarty CA, et al. Adaptation of WHOQOL as health-related quality of life instrument to develop a vision-specific instrument. Indian J Ophthalmol 2000;48:65-70.

34 Cunningham ET Jr. Uveitis in children. Ocul Immunol Inflamm 2000;8:251-61.

35 Rauz S, Stavrou P, Murray PI. Evaluation of foldable intraocular lenses in patients with uveitis. Ophthalmology 2000;107:909-19.

36 Kaklamani VG, Vaiopoulos G, Kaklamanis PG. Behcet's Disease. Semin Arthritis Rheum 1998;27:197-217.

37 Read RW. Vogt-Koyanagi-Harada disease. Ophthalmol Clin North Am 2002; 15:333-41.

38 Luisetti M, Beretta A, Casali L. Genetic aspects in sarcoidosis. Eur Respir J $2000 ; 16: 768-80$ 